Fecha de recepción: febrero 2013 Fecha de aceptación: julio 2013 Versión final: diciembre 2014

\section{Teatro: de Independiente a Alternativo. Una síntesis del camino del Teatro Independiente argentino hacia la condición de alternativo y otras cuestiones inevitables}

Roberto Perinelli ${ }^{\star}$

\begin{abstract}
Resumen: Aquí presento una síntesis del camino del Teatro Independiente Argentino hacia la condición de alternativo y otras cuestiones inevitables. El tema de esta breve nota será el registro del camino del Teatro Independiente Argentino, aquel creado por el infatigable Leonidas Barletta en 1930, cuando fundó el Teatro del Pueblo, hasta la presente y para mí luminosa realidad de 2011. Durante el trayecto el movimiento fue mutando hasta adquirir una denominación que, hoy, considero más pertinente, la de teatro alternativo ${ }^{1}$. En esa travesía de ochenta años el movimiento fue creciendo y sorteando dificultades. Algunas generaron situaciones casi jocosas -los enfrentamientos con la prensa escrita, que desconocía a los independientes con un manifiesto desdén-, pero mucho más serios fueron los conflictos del movimiento con las administraciones gubernamentales que usaron del atributo de la censura, instrumento predilecto e imprescindible de los gobiernos de facto que padecimos en el siglo XX.
\end{abstract}

Palabras claves: arte - escena comercializada - grupo estable - prensa escrita - teatristas - teatro - teatro abierto - teatro alternativo - teatro del pueblo - teatro independiente - teatro musical - teatro oficial - tribus teatrales.

[Resúmenes en inglés y portugués en la página 90]

${ }^{(*)}$ Es uno de los 6 integrantes de la Fundación Somi, responsable de la dirección del renovado Teatro del Pueblo, cuna del teatro independiente. Participó del mítico Teatro Abierto del 81, y fue director de la Escuela Municipal de Arte Dramático. Trabajó en el San Martín y estrenó casi todas las obras de teatro que ha escrito. Recibió innumerable cantidad de premios, y actualmente también se destaca como jurado del premio Trinidad Guevara y como consejero del Instituto Provincial del Teatro.

Los historiadores le conceden al Teatro Independiente Argentino una vida cercana a los treinta años. A medida que transcurrieron esas tres décadas el movimiento sintió crecer a su lado a quizás su peor enemigo, menos manejable que los que mencioné más arriba: la necesidad de cambio, el imperioso mandato de ceder respecto a sus rígidos postulados iniciales, los creados en primer término por el Teatro del Pueblo -la obligación de todos integrantes de cultivarse moral y físicamente; de aportar el trabajo como única contribución; de figurar en la plana sin ninguna distinción, compartiendo todos la misma categoría; la 
obligación de rechazar todo intento de profesionalización-, habida cuenta que el sostenimiento de esos preceptos de origen parecía condenarlo al anacronismo. No se puede dar una fecha que marque con exactitud la extinción del movimiento independiente en los términos que había imaginado Barletta y que fueron copiados, aun con matices particulares, por todas las agrupaciones que fueron creadas luego del germen inicial del Teatro del Pueblo. Se trató de un lento proceso de desgaste, de búsqueda de soluciones intermedias para conciliar los fundamentos con los mandatos de la realidad más inmediata, aunque, en opinión de Pedro Asquini, integrante de la línea más dura de la corriente, el cambio se aceleró rápido con la creación de tres canales de televisión durante la década del sesenta, que sumado a un primero que ya existía, el primitivo Canal 7, entonaron el canto de sirena que atrajo a actores y actrices que por acción de esa convocatoria fueron inducidos a pensar en la profesionalización.

Para seguir con este pequeño repaso (somero, de ningún modo pretendo agotar el tema) de la actividad escénica del Teatro Independiente, cuando en 1930 un grupo de teatristas -término maravilloso que retrata una condición profesional vasta, no atada a algún rubro específico sino vinculado con todos los que tienen competencia con la escena-, comenzó el camino que ha dejado rastros indelebles en la historia de nuestro teatro, debo señalar algunos de los puntos, acaso los más significativos, en que el movimiento tuvo necesidad de enfrentar desprecios, represiones y censuras. Los postulados de libertad de expresión artística que habían elaborado y los objetivos de creación de un teatro de arte que debía oponerse a una escena comercializada y banal, atrajeron el rechazo de quienes habían llevado al teatro porteño (no me atrevo a usar el gentilicio argentino, porque sólo me basaré en lo ocurrido en la ciudad de Buenos Aires) a ese punto de decadencia que los independientes buscaban desterrar. El desprecio de algunas figuras emblemáticas de ese teatro decadente (Vacarezza, Novión) fue inmediato; asimismo, a poco de andar, el movimiento debió enfrentar las primeras iras oficiales. Un hecho producido por la revolución castrense de 1943, el desalojo del Teatro del Pueblo del edificio de la avenida Corrientes (donde años después se levantó el Teatro San Martín), que le había sido concedido por la municipalidad de entonces, es acaso ejemplo del primer encontronazo entre los artistas independientes y los funcionarios gubernamentales filofascistas, que vieron en Barletta y su grupo a peligrosos propagandistas de las ideas de la izquierda.

El enfrentamiento se agudizó con la llegada del primer peronismo (1946), un movimiento que nunca concilió con los independientes. Por lo contrario, fue afán de unos y de otros la producción de actos para desacreditarse y es clave en esta pelea el estreno de El puente, en 1949, la obra de Carlos Gorostiza que mostraba la presencia de una sociedad formada por clases sociales antagónicas, una situación que el peronismo negaba existiera en la Argentina justicialista. La cuestión contiene sabrosos aspectos anecdóticos que marcan la guerra sin cuartel que, desde el bando oficial, comandaba Alejandro Apold, secretario de prensa del gobierno pero al parecer con capacidad de intervención punitiva en otros terrenos de la comunicación pública ${ }^{2}$. La posición de los independientes, contestataria, denunciante, a veces panfletaria $y$, era cierto, con frecuencia muy apegada a las ideas propugnadas por la izquierda más extrema, provocó por supuesto el fastidio de ese primer peronismo anticomunista, que para denigrar a los independientes los calificaba de "vocacionales" o, peor, de "filodramáticos". 
Las administraciones posteriores, que no contaron con el legítimo aval de las urnas que podía exhibir el peronismo, o acaso por eso mismo, por su origen fraudulento, mostraron aun mayor inquina e interés en silenciar al movimiento. En este sentido circula en librerías un sabroso libro de memorias de Pedro Asquini, donde cuenta con el humor de los apasionados sus éxitos y fracasos en el trance de eludir para su grupo, el mítico Nuevo Teatro que fundó junto con Alejandra Boero, la persecución ideológica del Estado y el afán puesto en conseguir una condición de visibilidad que con desdén le negaban el oficialismo y la prensa escrita ${ }^{3}$.

En esta rápida enumeración de las interrupciones institucionales que padecimos los argentinos (rasgo indigno de nuestro siglo XX), que afectaron de distinto modo y con diferente rigor el trabajo del Teatro Independiente, se debe subrayar a la dictadura de Juan Carlos Onganía, "revolución argentina" (me niego a las mayúsculas) iniciada en 1966 y muy afecta a corregir la conducta de ciudadanos y ciudadanas, a los cuales se los quería con pelo corto y faldas largas. El moralismo de la gestión se aplicó en todos los campos del arte y por supuesto puso piedras en el camino de los independientes que, cabe decirlo, iban entrando, muchos sin saberlo, en su última etapa, cuando las circunstancias indicaban que había de tomar decisiones: mutar o seguir sosteniendo principios que ya sonaban impropios para la época.

Cierra este triste recorrido el siniestro terrorismo de Estado impuesto el 24 de marzo de 1976.

El autollamado "proceso de reorganización nacional" (también me niego a las mayúsculas), de ánimo represor en todos los órdenes, no tuvo en consideración la capacidad de convocatoria de esos teatristas que a esa altura, la del año 1976, ya habían adoptado el cambio (se habían profesionalizado) 4 , y entonces podían prescindir de su denominación de independiente para ser reemplazada por la de alternativo, término que usaré en adelante. En el caso de las artes representativas, la dictadura del 76 puso la atención represiva más precisamente en la televisión (las fuerzas armadas se repartieron los cuatro canales existentes y controlaron su emisión), y en el cine, prohibiendo la actuación de directores, guionistas, actores y actrices que en muchos casos salvaron su vida con un oportuno exilio que no impidió, lamentablemente, que algunos engrosaran la triste lista de desaparecidos. El proceso militar desconocía, sin duda, el duro entrenamiento de los teatristas que por años habían enfrentado a las administraciones autoritarias. Ignoraba que, como se esbozó más arriba, la pelea formaba parte de la tradición teatral y el ingreso a las filas de la actividad, a través de la puerta que antes había abierto el Teatro Independiente y en los setenta lo hacía la escena alternativa, incluía la implícita aceptación de los viejos principios de lucha que los independientes habían dejado como legado. Aquí, en la adhesión a esta conducta heredada, debe encontrarse, a mi criterio, el acta de nacimiento de Teatro Abierto, el movimiento que reavivó la controversia contra un gobierno dictatorial de una manera original aunque mucho más peligrosa: esta vez el enemigo no era un censor inflado de poder y de soberbia sino un régimen que había instituido como método el terrorismo de Estado. Los teatristas que generaron el movimiento -con orgullo informo que fui uno de ellos-, hicieron un estudio del páramo (el proceso militar había frenado un vigoroso crecimiento del teatro alternativo, producido a comienzos de la década del setenta, que auguraba lo mejor si no hubiera sido interrumpido por los acontecimientos de 1976) ${ }^{5}$, y 
en cambio de caer en el desaliento encontró el estimulo en una frase: "algo tenemos que hacer". Es historia conocida cómo fue fraguando esa decisión. Se la ha contado en varios artículos - algunos llevan mi firma -, en versiones que a veces muestran diferencias de matices, tal como la que relata Carlos Gorostiza en su libro de memorias El merodeador enmascarado, que no coincide con opiniones que dicen que Teatro Abierto tuvo otros orígenes $^{6}$. No es este el lugar ni es mía la intención de confrontar, marcar las diferencias y arriesgar un dato de constitución indiscutible, ya que como he manifestado en alguna oportunidad Teatro Abierto se ha consolidado como un mito pétreo que no admite demasiadas indagaciones, conformes todos con el lugar de acontecimiento legendario que le hemos asignado. Ahí está y sospecho que así quedará, con estatura de mito, en la historia de nuestro teatro argentino.

Cabe, eso sí, señalar que la dictadura pagó caro el desdén por la influencia del teatro. Cuando reaccionó, Teatro Abierto ya era una realidad imposible de reprimir (aun para criminales que usaban el exterminio con total desaprensión), y el incendio intencional del Teatro del Picadero en agosto de 1981, primera sede de Teatro Abierto, fue más un signo de impotencia de la dictadura que una verdadera amenaza para el suceso, que a partir del atentado aumentó en grado exponencial su capacidad de convocatoria. Hay imágenes fotográficas y cinematográficas que registran con elocuencia las largas colas de espectadores frente al Tabarís, ámbito que reemplazó al recinto quemado, elegido entre casi veinte teatros que habían ofrecido sus instalaciones.

Acaso ha merecido poca consideración uno de los más trascendentes actos de gestión del presidente constitucional Raúl Alfonsín, que fue la disolución, el 22 de febrero de 1984, del nefasto Ente de Calificación Cinematográfica, predio de oscurantistas funcionarios que exceden el calificativo de retrógrados, y la derogación de la ley 18019 que regía desde enero de 1969 y llevaba la firma del presidente de facto de entonces, Juan Carlos Onganía, y su ministro del interior, Guillermo Borda. Esta medida liberaba a la exhibición cinematográfica de una norma restrictiva que le había dado mil disgustos. Bastaría mencionar algunos títulos del director sueco Igmar Bergman o de nuestro Armando Bo que, cuando por azar o vaya a saberse por qué razones, pudieron ser exhibidos, mostraban evidentes señales de mutilación censural. Esta liberación de trabas, que incluía naturalmente no sólo a la exhibición sino también a la realización cinematográfica, quitaba obstáculos a toda la producción artística en general, entre ellas, claro, la escénica. Y sin duda esto estimuló el estallido, el bing bang que conmovió a todo el teatro posproceso e hizo blanco más preciso en la escena alternativa. El sacudón no fue inmediato, se produjo luego de un período de calma que fue claramente un lapso para el acomodo de las piezas. Comenzados los noventa, cuando se esperaba la recuperación del campo alternativo como una continuidad de las poéticas que se habían mostrado en las ediciones de Teatro Abierto7 ${ }^{7}$, hizo su ingreso una generación también contestataria pero que optó por operar en otro sentido: abriendo caminos inesperados y dispersos buscó recuperar el teatro como factor de entretenimiento y de diversión, llevando a cabo algunas experiencias inéditas y hasta ahí poco frecuentadas por el teatro de Buenos Aires, que, con diferente fortuna, intentaron romper con un pasado tan cargado de compromiso político para reemplazarlo por lo lúdico y placentero. Estas iniciativas, congregadas en espacios no convencionales que ahora son 
recuerdo (el Parakultural, por ejemplo) y que han quedado en la historia como emblemáticos, consistían en espectáculos de café-concert ${ }^{8}$, apoyados éstos en el alto y cautivante nivel de histrionismo de los actores, el infaltable teatro de la imagen (que sonó mucho y dio poco) y los emprendimientos inspirados en la estética de Eugenio Barba (menos próspera todavía).

Renglón aparte se merece el teatro musical, que a partir de esas fechas inicia un crecimiento hoy ampliamente consolidado. Pepe Cibrián, líder del movimiento, reestrena en 1987 en un espacio oficial, el Teatro Presidente Alvear, su comedia musical Aquí no podemos hacerlo, con la intención, precisamente, de mostrar un espectáculo que contradice la dificultad expresada en el título9 . La fuerza de voluntad de Pepe Cibrián se expresó en sus declaraciones -"este es un género casi virgen en nuestro país, en el que está todo por hacerse. No me cansaré de insistir en que debemos conseguir un musical con tempo y ritmo locales" 10 -, y se robusteció cuando formó equipo con el músico Ángel Mahler, compañero de aventuras escénicas desde entonces.

En suma, en esta primavera democrática, se soltaron las amarras y, como curiosa consecuencia, todos, teatristas, público y periodismo, embistieron contra el texto, como si éste, acaso el rubro que más había mordido el pan duro de la pelea, no tuviera derecho a saborear el champagne y las masitas de la fiesta. Los autores habían generado Teatro Abierto, eso nadie lo discutía, pero parecía haberse decidido que ahí habían terminado con su misión, ahora el escenario era el espacio para el festejo, para la diversión que los textos no parecían proponer.

Resucitaba de este modo un debate, postergado por la larga noche de la dictadura, que había nacido en los sesenta, cuando los golpes contra el texto tenían un blanco más preciso: se atacaba al realismo de Ricardo Halac, Tito Cossa, Carlos Somigliana, entre otros, denostado con la calificación de naturalismo o, peor, de costumbrismo decadente, y se defendía el "absurdismo" o la neovanguardia nacida en la posguerra europea, que nos llegaba de París, vía Ionesco, vía Adamov y, sin que le cupiera el término, cosa que descubrimos después, vía Samuel Beckett. Aquí el periodismo, encabezado por algunas figuras que aun hoy tienen voz en la prensa, enarbolaban las piezas de Griselda Gambaro como las representantes de la nueva corriente (no sé si la autora acepta o aceptó ese liderazgo, al menos yo no dispongo de datos aclaratorios). Este debate, que recuerda a la célebre polémica francesa del siglo XIX entre académicos y románticos, cita obligada en cualquier libro de historia teatral, ha sido estudiada con precisa documentación por Osvaldo Pellettieri, por lo que recomiendo, en caso de interés de profundizar la información, acudir a la lectura de ese libro ${ }^{11}$.

Me cabe denunciar, sin embargo, que ese periodismo, que ahora, en el 2011, cuando el texto ha superado mucho del terreno perdido, se muestra más cauto y respetuoso del dramaturgo, nunca imaginó la fugacidad del debate, ya que a poco las corrientes estéticas que se quisieron enfrentadas fueron encontrándose, y los autores hicieron uso de la libertad de los creadores y se apropiaron de procedimientos de uno y otro estilo, hasta el punto que es imposible calificar a La nona, de Roberto Cossa, de realista o naturalista, como tampoco se puede tachar de "absurdista" a La malasangre, la espléndida pieza de Griselda Gambaro. Y son sólo dos ejemplos, tal vez los mejores. 
Volviendo al clima exaltado, eufórico, que tiñó toda la década del noventa, es posible definir que la situación incidió en las tres zonas en que estaba dividida la actividad teatral porteña: el teatro oficial, el comercial y el alternativo. Las fronteras eran bastante claras entonces y son muy borrosas hoy, debido al intercambio que se ha producido, cuando, por ejemplo, la escena comercial se nutre con directores que se desarrollaron en el campo alternativo, mientras los actores frecuentan cualquiera de las tres áreas sin ninguna dificultad. Se debe admitir que el sacudón de la primavera democrática alteró muy poco el andar del primero, el teatro oficial, premiado por una insólita comodidad durante toda la dictadura militar y por lo tanto valido de un repertorio que extrañaba le fuera permitido por las autoridades culturales del proceso. Uno de los títulos canónicos de esa etapa del Teatro San Martín (al fin y al cabo cuando hablamos de teatro oficial hablamos de ese recinto), fue la obra de Ibsen Un enemigo del pueblo, un texto que fue festín de censuras de países con ánimo mucho menos restrictivo que la del autollamado proceso y que el San Martín representó con un éxito casi sin precedentes (¿acaso porque el público ya estaba queriendo escuchar denuncias?).

El teatro comercial comenzó a entender (claro que no con el convencimiento total que tiene ahora), que los buenos negocios también se consiguen produciendo buen teatro.

Al mismo tiempo la escena alternativa fue recuperando la fuerza que le había sido frenada por la dictadura, y volvió vigorosa y versátil. Hoy sigue siendo el área de mayor empuje, aun cuando el teatro comercial ha ganado terreno poniendo en escena con gran solvencia buenos títulos de la dramaturgia internacional, y cuando, por una extraña ley de las compensaciones, y por razones que servirían para otra nota, el teatro oficial muestra una decadencia que lo ha desplazado de su condición de faro rector. El San Martín ya no es el San Martín se dice en la calle, y parece que la frase no es una irreflexiva opinión de circunstancias, sino corresponde a lo que ocurre en la realidad.

De este modo el teatro de Buenos Aires entró en el nuevo siglo, que a medida que fue avanzando produjo otras prósperas transformaciones, entre ellas la venia para que los autores denostados, portando como arma una buena literatura dramática, pudieran por fin sumarse a la fiesta. Entró en el juego una nueva generación de dramaturgos, que le dio tanto aliento al rubro de modo que la aceptación incluyó también a muchos de los autores próceres, aquellos que adquirieron visibilidad con Teatro Abierto. Fenómeno único quizás. La historia del teatro registra siempre un inevitable efecto de desplazamiento, de reemplazo de unos autores por otros, que en el caso porteño no se dio y no muestra signos de aparición; los jóvenes, algunos ya no lo son tanto, y los viejos comparten la cartelera. A este ritmo la ciudad, poco a poco, se fue transformando en un asombroso polo de la escena en lengua castellana. Los continuos reclamos, hasta ahora infructuosos, para declararla "capital del teatro en lengua castellana", parecen fundados o, al menos, no pueden juzgarse como una pretensión desatinada. Una ciudad que ofrece, un fin de semana, la cantidad aproximada de trescientos espectáculos teatrales de la más variada gama, que compiten en pie de igualdad con rivales peligrosísimos, tal como la música, el cine, el fútbol y la televisión (que siempre invita a quedarse en casa), y que sin embargo consigue convocar espectadores como para mantener cubierto con un buen porcentaje el con frecuencia pequeño aforo de casi doscientos espacios teatrales, merece sin duda esa consideración especial. Estas circunstancias de cantidad, y también de calidad ya que es alto 
el porcentaje de espectáculos que superan, algunos con holgura, las más altas exigencias artísticas, se dan, entre otras razones, por las particulares condiciones de representación que ha creado el teatro alternativo, que abandonó el concepto de "temporada" (que sigue sosteniendo la escena oficial y a rajatabla la escena comercial), y ofrece sus productos en una o dos funciones semanales, en cambio de las siete que exige el encuadre tradicional. Es difícil desentrañar cómo se llegó a esta fórmula: la representación de un espectáculo de pequeño formato (he visto obras que apenas superan los 30 minutos), sólo una o dos veces por semana, con la osadía de hacerlo en cualquier espacio teatralizado, galpones y hasta casas particulares, que suelen ser vivienda de uno de los responsables del espectáculo. También difícil resulta dilucidar la aceptación de los espectadores para acudir a estos lugares no convencionales perdiendo muchas de las comodidades que encuentra en una sala tradicional, desde la confortabilidad de las sillas hasta las condiciones climáticas, ya que con frecuencia son ámbitos frescos en invierno y ardientes en verano.

También suena asombroso cómo se fue modelando esta nueva forma de representación, ya que nadie teorizó al respecto, fue la realidad la que impuso sus reglas y la escena alternativa las fue adoptando. Se sabe, en afán de rastrear el origen del modelo, que al menos no fue imitación de ejemplos externos, como sí lo fue, durante las primeras décadas del siglo pasado, la apropiación del "género chico", en realidad creación de tres desesperados empresarios españoles -Juan José Luján, Antonio Riquelme y José Vallés-, que Buenos Aires copió para darle condiciones de crecimiento al fascinante fenómeno del sainete. Para quienes desconocen el tema o no lo conocen en profundidad, el género chico de comienzos del siglo XX (que los historiadores consideran que debería llamarse, con mayor propiedad, género breve), se apoyó en una programación de obras cortas, que no excedían la hora, de modo de poder ofrecer cuatro piezas cada día de función. El precio bajo de las entradas convocó al público humilde, el inmigrante que desde no hacía mucho tiempo vivía en la Argentina y traía en las entrañas el gusto por el teatro, al cual se le brindó historias afines con su nueva cotidianeidad: la vida esforzada de los conventillos, la llegada del tango al campo popular, el roce con la delincuencia menor y los intentos de "tanos" y "gallegos" por adaptar el idioma a la jerga porteña, lo que producía el viejo efecto cómico del malentendido, tan usado por el teatro de todos los tiempos. Así nació, creció y murió, a fines de los 30, el sainete criollo, hijo del español.

Sin que todavía el sistema de representación que el teatro alternativo emplea hoy tenga nombre que lo distinga (algún académico ya lo bautizará), reitero que un espectáculo de este rubro, aun exitoso, se ofrece sólo una o dos veces por semana. El eventual éxito no alienta a los teatristas a ir mucho más allá, sino que éstos apuestan a que, obedeciendo a la pausada cadencia, la permanencia en cartel sea más extensa y que un espectáculo atractivo supere el año de representaciones, de modo que es posible encontrar en la convocatoria del año siguiente (generalmente colgada de la web) el alarde de una nota de gran relieve tipográfico que indica "segunda o tercera temporada".

Este modelo concita críticas, claro. Los viejos actores (y esto de viejos está dicho sin ánimo peyorativo), ven una dificultad en la necesidad de sostener la continuidad de un personaje encarnándolo sólo una vez a la semana, circunstancia que parece no importarle a las nuevas camadas de intérpretes, que son legión, que aprovechan precisamente esta pausada manera de andar el camino para integrar dos o tres elencos a la vez, para lo cual sólo tienen 
que tener el cuidado de que no haya coincidencia de horarios, ya que la omnipresencia no se enseña, todavía, en ningún taller de formación dramática. El tradicional saludo, sincero o convencional, al actor amigo que acaba de terminar la función y se asoma al hall del teatro, debe hacerse a las apuradas, porque a éste le resta poco tiempo para tomarse el taxi que lo llevará al otro teatro donde dentro de media hora deberá interpretar a un personaje distinto del que acabamos de ver.

Otros críticos del fenómeno alegan que esta libertad de movimientos ha agudizado una de las viejas carencias del teatro de Buenos Aires: la casi inexistencia de grupos estables. Y con eso, la debilitación del concepto de militancia del viejo teatro independiente, germen real, repetimos, de todo este movimiento alternativo. Es cierto el reparo, lo que no sé es si le cabe la condición de reproche. Los actores no parecen felices sintiéndose atados a un proyecto de conjunto que les exigiría dedicación exclusiva. El libre albedrío le permite al actor, también al director e incluso al autor, vivir experiencias de distinto diseño, porque, si de algo más puede vanagloriarse la escena porteña, es de su condición versátil, de la multiplicidad de estilos y poéticas diferentes que viven en normal convivencia, sin dogmas limitativos.

Tal vez podría hablarse de islas, de tribus, de una cantidad imprecisa de integrantes vinculados por tendencias estéticas comunes que, uno sabe, sólo estarían dispuestos a embarcarse en aventuras teatrales que encajen con esos intereses. Pero también esto es relativo, un prejuicio que a veces es derrotado por la realidad. Bastantes sorpresas he tenido cuando asistí a ver el trabajo de tal, reconocido enemigo del costumbrismo, y vi un espectáculo afín con el mejor costumbrismo.

Este nuevo modelo de representación ha separado al teatro alternativo del comercial y del oficial, pero aquí se acaban los límites. Siempre queda abierta la posibilidad de que el actor, el director, raramente el autor (es quien en este asunto lleva la peor parte), salte la valla y, beneficioso salario mediante, actúe en alguno de esos dos campos donde circula el dinero seguro. Hay quienes acusan de traición, marcando estos pasos como una renuncia al teatro alternativo, usado, se acusa, como las deportivas divisiones inferiores para luego jugar en las grandes ligas. Con las excepciones que puede haber, estimo que estas escapadas no suelen ser definitivas, son simples trasnochadas toleradas por el cónyuge, porque apenas se termina de actuar o de dirigir en el espléndido escenario del Teatro San Martín, con todos los medios técnicos a disposición, los actores, los teatristas debería decir, vuelven a la ratonera de su infancia teatral, con sus modestas e incómodas sesenta butacas, donde verán cómo se hace teatral una obra propia, la de un dramaturgo nacional o extranjero que lo ha conmovido o la versión teatral de un relato de Arlt o Dostoievski. 


\section{Notas}

1. Hay quienes le dan otra denominación: teatro de arte, under, off, etc. Todas son válidas, sinónimos de alternativo.

2. Al respecto recomiendo la consulta al libro de Osvaldo Pellettieri, Una historia interrumpida. Teatro Argentino Moderno (1949-1976), Buenos Aires, Editorial Galerna, donde trata el tema de El puente.

3. Asquini, Pedro. 1989. El teatro que hicimos. Buenos Aires. Editorial Rescate. Rafael Cedeño Editor.

4. La Real Academia Española define profesión como "empleo, facultad u oficio que alguien ejerce y por el que percibe una retribución”. En el caso de aplicarla a esta área del teatro porteño, la definición debería aclarar que la retribución no pesa en el momento en que los teatristas eligen el proyecto, sino que se tienen en cuenta las posibilidades artísticas que el mismo contiene.

5. En medio del clima enrarecido del proceso se registra el estreno de cuatro expresiones teatrales de altísimo nivel. Merecen ser mencionadas. Una versión de Los Siete locos, la novela de Roberto Arlt que fue llevada a escena por Rubens Correa e inauguró el Teatro del Picadero, a poco de ser incendiado por la represión por ser la primera sede de Teatro Abierto; el estreno de La nona, de Roberto Cossa; de Visita, obra de Ricardo Monti dirigida por Jaime Kogan en el Teatro Payró; y una espléndida puesta de una directora debutante, Laura Yusem, que montó Boda blanca, del polaco Tadeusz Razewich.

6. Gorostiza, Carlos. 2004. El merodeador enmascarado. Algunas memorias. Buenos Aires. Seix Barral.

7. Hay debate acerca de cuántas fueron; se estima que las primeras tres versiones -1981 , 1982 y 1983-, conservaron bastante el formato de origen, luego, ya con algunos teatristas de Teatro Abierto involucrados como funcionarios del gobierno de Alfonsín, continuó con otras formas y maneras que acaso legítimamente pueden reclamar la condición de continuadores del fenómeno.

8. Como define Patrice Pavis en su famoso Diccionario del teatro (1980, España. Ediciones Paidós), el café-concert, que él llama café-teatro, está constantemente en conflicto con el teatro establecido y reconoce ilustres antecedentes, desde las tabernas de la Edad Media hasta los cafés de los filósofos del siglo XVIII.

9. Aquí no podemos hacerlo, la primera comedia musical donde Pepe Cibrián aplicó sus conceptos, fue estrenada en 1978 en el Teatro Embassy. El malogrado comienzo, la sala vacía durante un mes, fue superado por una oportuna crítica del periodista Daniel López en el diario La Opinión, que calificó al espectáculo como "el primer gran musical argentino". 10. Declaración citada en el libro de Pablo Gorlero Historia de la comedia musical en la Argentina, desde sus comienzos hasta 1979, editado en Buenos Aires, en el año 2004, por Marcelo Héctor Oliveri Editor.

11. Pellettieri, Osvaldo. 2001. Teatro XX y la polémica entre realistas reflexivos y neovanguardistas. Buenos Aires. Editorial Nueva Generación y Facultad de Filosofía y Letras (UBA). 
Summary: The article presents a synthesis of the argentine Independent Theatre path toward the alternative condition and other inevitable issues. The subject of this paper will record the Argentine Independent Theatre way -the one created by Leonidas Barletta in 1930- from the People's Theater foundation to present. Along the way, the movement was mutating since the acquisition of its present name: the alternative theater. In this journey of eighty years the movement was growing and avoiding difficulties. Some situations generated almost humorous situations -clashes with the press who treated the independent with a manifest contempt- but were much more serious conflicts with government that used the governmental attribute of censorship, beloved and indispensable instrument of facto governments in the twentieth century.

Keywords: alternative theater - art - independent theater - marketed scene - musical theater - official theater - open theater - playwritters - press - stable group - theater of the people - theater tribes - Theatre.

Resumo: O escrito apresenta uma síntese do caminho do Teatro Independente Argentino até a condição de alternativo e outras questões inevitáveis. O tema desta breve nota será o registro do caminho do Teatro Independente Argentino, aquele criado por o infatigável Leônidas Barletta em 1930, quando fundou o Teatro do Povo, até a presente e luminosa realidade de 2011. Durante o trajeto o movimento foi mudando até adquirir uma denominação que hoje considero mais pertinente, a do teatro alternativo. Nessa travessia de oitenta anos o movimento foi crescendo e sorteando dificuldades. Algumas geraram situações quase jocosas -os enfrentamentos com a prensa escrita, que desconhecia aos independentes com um manifesto desdém - mas muito mais sérios foram os conflitos do movimento com as administrações governamentais que usaram o atributo da censura, instrumento predileto e imprescindível dos governos militares no século XX.

Palavras chave: arte - cena comercializada - grupo estável - prensa escrita - teatristas Teatro - teatro aberto - teatro alternativo - teatro do povo - teatro independente - teatro musical - teatro oficial - tribos teatrais. 